\title{
Repeated job quits: stepping stones or learning about quality?
}

\author{
Anne C Gielen
}

Correspondence: Gielen@ese.eur.nl Erasmus University Rotterdam and IZA, Erasmus University Rotterdam, P.O. Box 1738, 3000 DR Rotterdam, The Netherlands

\begin{abstract}
Increasing labor mobility is high on the political agenda because of its supposedly positive effects on labor market functioning. However, little attention has been paid to information imperfections, and to what extent they limit potential efficiency gains of labor mobility. When the quality of a new job offer is known ex ante, job quits serve as a stepping stone to better jobs. Yet, if job quality is only observed ex post, job quits may lead to worse matches. This paper argues that actual job quit behavior is characterized by a mixture of both, and investigates the relative empirical content of both extremes in quit decisions. A variance decomposition shows that for nearly $70 \%$ of job quits job quality was observed ex-ante; the remaining $30 \%$ was learned ex post. Hence, stimulating job mobility mostly improves labor market outcomes, though governments may aim to further reduce information imperfections in order to maximize the efficacy of labor policies.

JEL codes: J28, J62.
\end{abstract}

Keywords: Job search; Job satisfaction; Labor mobility

\section{Introduction}

During recent decades, enhancing labor market flexibility has been one of the main pillars of European labor market policy. A flexible labor market is considered desirable because of its ability to quickly adapt to fluctuations and changes in society, leading to more efficient labor market outcomes. It allows, for example, workers to move jobs in order to build a career or to find a job that better matches their personal and family circumstances. However, this is only true if there is sufficient information available to workers to identify good jobs. Looking at some particular patterns in labor mobility, one may wonder whether this is the case. Labor mobility patterns across workers exhibit a great deal of variety (see e.g. Kambourov and Manovskii (2008)). Long-term employment relationships are quite common, yet some workers are involved in many job quits within a short time period (Farber (1999)). Given the recent evidence that workers usually gain in job satisfaction and obtain higher wages after a job quit (e.g. Perez and Rebollo (2005); Chi et al. (2008)), the fact that many decide to change jobs again shortly after an initial quit raises the question whether these job changes always contribute to better matching efficiency or whether some changes simply constitute a relocation of labor without any increase (or even a loss) in match quality. In the latter case, policy aimed at stimulating job mobility may not improve labor market outcomes as much as is expected by policy

(c) 2013 Gielen; licensee Springer. This is an Open Access article distributed under the terms of the Creative Commons Attribution License (http://creativecommons.org/licenses/by/2.0), which permits unrestricted use, distribution, and reproduction in any medium, provided the original work is properly cited. 
makers. Better information about the nature of job mobility is essential for formulating effective labor policy.

From a theoretical point of view, job changes can be explained by the presence (or absence) of ex ante information about job quality. At the one extreme, job quality may be perfectly observable at the time a job offer arrives, and hence workers may decide to quit (again) if they receive an offer which is better than their current job. This can be denoted the stepping-stone mechanism, based on the on-the-job search theory by Burdett (1978). At the other extreme, repeated job quits can be explained by the complete absence of ex ante information about job quality - the so-called learning model pioneered by Jovanovic (1979). In this model, job quality is revealed over the time spent in the job. In case job quality turns out to be lower than expected, workers may decide to leave the job again, although the quality of a new job offer cannot be ascertained in advance. Obviously, these two theories can be considered two ends of a continuum representing the degree to which ex ante job quality information is available. In practice, workers may decide to change jobs in a situation where some information about job quality is known ex ante, and the rest has to be learned while in the job. This paper argues that actual job quit behavior is characterized by a mixture of both. The main aim of the paper is to study the extent to which repeated job quits can be explained by the stepping-stone theory versus the learning model, and hence to determine the relative importance of both models in job quit decisions. This information is crucial for policy makers aiming to improve labor market functioning by stimulating labor mobility.

Studying the relationship between job mobility and worker-job match quality is not easy, since match quality is usually not observable. Earlier studies have looked at wages as being an observable outcome of unobserved match quality. Job quits are usually found to be associated with wage gains (Perez and Rebollo (2005), Light (2005)), though not neccesarily (Postel-Vinay and Robin (2002), Neumark (2002)). In addition, a job quit may improve the job match if a job change facilitates moving from a temporary position to a permanent position (Booth et al. (2002)) or if it leads to an improvement of other nonmonetary aspects of the job (Altonji and Paxson (1986)). Munasinghe and Sigman (2004) point to the importance of a fundamental search process in order to explain these positive effects on match quality, since unobservable individual effects alone cannot explain the relationship between mobility and wages. A study by Light and McGarry (1998) used the NLSY data to empirically distinguish between several models explaining the relationship between job mobility and wage outcomes. They find that after taking into account the role of individual fixed effects and the ex ante observability of job quality there is still a significant effect of mobility on wage outcomes, which they interpret as evidence for the learning model. However, these previous studies looked for evidence for one model by eliminating one-by-one the other models. This paper will build on this by investigating the relative importance of each model.

Furthermore, the current paper will focus on job satisfaction as a measure for the workers' perceived match quality, as this not only includes the monetary but also the non-monetary aspects of the job (see section 2.3 .1 for a more detailed discussion) ${ }^{1}$. Earlier studies have shown that people with low job satisfaction are more likely to quit (e.g. Freeman (1978), Akerlof et al. (1988), Clark et al. (1998), Sousa-Poza and Henneberger (2004), Levy-Garboua et al. (2007), Bockermann and Ilmakunnas (2009), Green $(2010))^{2}$. However, little is known about why sequential job quits might arise. Sequential 
job search might arise to achieve better occupational matching (e.g. McCall (1990)). For example, Neal (1999) shows that workers always change careers first before they search for their preferred firm to work in. However, sequential job search might also be the result of a poor new job match. We can learn more about this by looking at ex post job quality. Note that there may be other models which can explain job quit behavior. For example, the mover-stayer model which argues that some underlying personality characteristics determine whether someone quits his job often or not. However, the study by Light and McGarry (1998) has shown that the relationship between job mobility and match quality is hardly changed once you control for individual fixed effects. Given the marginal relevance of this model for explaining post-mobility job quality, the current paper will focus only on the two most important models. The role for unobserved individual effects will, however, shortly be addressed when discussing the results.

This paper investigates the role of ex ante information imperfections in job quits using data from the British Household Panel Survey (BHPS), which provides information to distinguish worker-initiated job quits from other job separations. Information about repeated job quits is studied to observe how match quality is affected by subsequent job changes. If match quality always improves following each job quit, then job quit behavior can be considered a stepping stone mechanism, contributing to matching efficiency. Alternatively, in the learning model where job quality is not observable ex ante there is more variation in match quality in the new job. Job quality improves only in expected terms; some workers' match quality may improve after a job change while for others it may worsen unexpectedly. By using the theoretical predictions from both models, a variance decomposition of job satisfaction in the new job allows me to determine the relative importance of both models. The results illustrate that nearly 70 percent of job characteristics can be observed and exploited to improve job quality by changing jobs (stepping-stone), while there is a 30 percent chance that the new match turns out to be different than expected, either better or worse (learning).

The structure of the paper is as follows. The next section presents a simple theoretical model which sets out possible motivations for repeated job quits. Section 3 describes the data and some stylized facts. In Section 4, the results from the empirical analysis are presented; and Section 5 concludes.

\section{Theoretical model}

This section presents a model, based on Jovanovic (1984), which combines elements of the stepping stone model (Burdett (1978)), where alternative jobs vary over time due to the arrival of new job offers, with elements of the learning model (Jovanovic (1979)), where the value of the current job match varies due to learning. For presentational simplicity the model is rather stylized (e.g. excluding worker heterogeneity and endogenous changes in match quality), but it captures the essence of the alternative mechanisms that drive worker mobility ${ }^{3}$. For the purpose of this paper this is sufficient since this section only serves to provide some intuition for how we can identify the relative importance of both models in the data.

For simplicity, workers are assumed to be infinitely lived and risk neutral optimizers. They search in the labor market for their optimal job match, based on several job characteristics such as the wage, working hours, benefits, location, job security, and working conditions. The quality of the match, denoted by $\mu$, is drawn from a normal distribution 
with mean $\bar{\mu}$ and variance $\sigma_{\mu}^{2}$, i.e. $\mu \sim \mathcal{N}\left(\bar{\mu}, \sigma_{\mu}^{2}\right)$. Workers can obtain information about the true match quality in two steps.

Before the start of the match, workers try to evaluate the quality of the match. This ex ante assessment $m=\mu+\epsilon$ is a noisy estimate of the true match quality $\mu$ due to $\epsilon \sim \mathcal{N}\left(0, \sigma_{m}^{2}\right)$. The smaller $\sigma_{m}$ the easier it is to make a good ex ante assessment of the true match quality. For example, workers' ability to assess the quality of a job may be imperfect ex ante due to the fact that the ex ante job quality anticipation differs from the way people ex post live the job (Stutzer and Frey (2008)). Put differently, the larger $\sigma_{m}$, the more has to be learned about match quality when the employment relationship is ongoing.

Once the employment relationship has started, in each period $i$ the worker can learn about the quality of the match, $x_{i}=\mu+v_{i}$, which is equal to the average quality of the match and a deviation from its average level $v$ where $v \sim \mathcal{N}\left(0, \sigma_{x}^{2}\right)$. Note that these deviations need not be positive, and can be negative as well. The revealed quality $x_{i}$ in each period $i$ is informative about the true match quality. Workers will update their beliefs about the quality of the job $\mu$ from the observations $m$ and $x_{1}, Y \ldots, x_{t}$. For observed values of $m$ and $x_{1}, \ldots, x_{t}$ the posterior distribution of $\mu$ is normal with mean

$$
J S^{*}(t)=E\left(\mu \mid m, x_{1} \ldots x_{t}\right)=\left[\frac{\bar{\mu}}{\sigma_{\mu}^{2}}+\frac{m}{\sigma_{m}^{2}}+\frac{\sum_{i=1}^{t} x_{i}}{\sigma_{x}^{2}}\right]\left(\frac{1}{\sigma_{\mu}^{2}}+\frac{1}{\sigma_{m}^{2}}+\frac{t}{\sigma_{x}^{2}}\right)^{-1}
$$

and variance $\left(\frac{1}{\sigma_{\mu}^{2}}+\frac{1}{\sigma_{m}^{2}}+\frac{t}{\sigma_{x}^{2}}\right)^{-1}$. The parameters $\sigma_{\mu}^{2}, \sigma_{x}^{2}, \sigma_{m}^{2}$, and $\bar{\mu}$ are known to the worker.

Let $W$ denote the present value of continuing in the current job which has perceived quality $J S^{*}$ after $t$ quality revelations, i.e. $W\left(J S^{*}(t)\right)$. New job offers arrive at rate $\lambda$, and each new job offer $m^{\prime}$ is evaluated as $J S^{*^{\prime}}(0)=E\left(\mu \mid m^{\prime}, 0\right)$. Since both $\bar{\mu}$ and $m$ are normally distributed, the quality of each new offer is also a draw from a normal distribution $F\left(J S^{*}\right)$ (see Jovanovic (1984)). Let $V$ represent the expected present value of future job quality of any randomly selected alternative job, i.e. the value of leaving the current job:

$$
V=W\left(J S^{*^{\prime}}(0)\right)
$$

There exists a set of $J S^{*^{\prime}}(0)$ for which the worker is indifferent between quitting his job and continuing in the job. This boundary of indifference can be characterized in terms of a reservation job quality $\widetilde{J}{ }^{*}$ which equates $W$ and $V$ :

$$
W\left(J S^{*}(t)\right)=V\left(\widetilde{J S^{*}}(0)\right)
$$

A worker will quit his job if he finds an alternative job which offers him an initial job quality $J S^{*^{\prime}}$ such that $V\left(J S^{*^{\prime}}(0)\right)>V\left(\widetilde{J S^{*}}(0)\right)^{4}$. Then, the quit probability can be expressed as follows:

$$
q\left(J S^{*}(t)\right)=\lambda\left(1-F\left[\widetilde{J S^{*}}(0)\right]\right)
$$

The extent to which workers can assess true job quality during the job search process before the employment relationship starts may vary between perfect observability and a complete absence of any ex ante job information. I discuss the first of these polar cases in the next subsection. 


\subsection{Stepping stone model}

The first extreme case is a situation where all the information about job quality is available ex ante, i.e. $\sigma_{m}=0$, and later output revelations do not provide additional information about match quality. If the quality realizations were observable at the time of hire then the model resembles the stepping stone model by Burdett (1978). When all information about job quality is available ex ante, perceived job quality is a constant and $W$ does not depend on tenure. Then, Equation (4) becomes as follows

$$
q\left(J S^{*}\right)=\lambda\left(1-F\left[J S^{*}\right]\right)
$$

which shows that a job change always leads to a new job that is at least as good as the previous job. Furthermore, note that $F(\cdot)$ is a cumulative distribution function, which is increasing in $J S^{*}$. As a result, Equation (5) is decreasing in $J S^{*}$, showing that workers in poor matches are more likely to change to a better job. All in all, when match quality is perfectly observable, repeated job quits serve as a stepping stone to higher quality jobs.

\subsection{Learning model}

The other extreme is the situation where no information about job quality is available ex ante, i.e. $\sigma_{m}=\infty$. In this situation, as is shown by Equation (1), all information about match quality has to be obtained from quality revelations - which can be both surprising or disappointing - while the employment relationship is ongoing (cf. Jovanovic (1979)). Hence, variation in job quality mostly comes from within the job (rather than across jobs). Hence, a worker will decide to quit his job if the revealed quality turns out to be lower than the expected alternative offer, as can be seen from Equation (4). Note that, because of the learning dimension, the new accepted job is not by definition better than the old job, but only in expected terms. Hence, changing jobs generally leads to a better match quality, but there is a certain risk that the match turns out to be worse than expected and that in fact new job quality falls below the quality of the previous job.

\subsection{Empirical implementation}

\subsubsection{Job satisfaction to measure match quality}

This paper exploits self-reported job satisfaction as a measure for unobserved job quality. Since true job quality is not observable, job satisfaction is not a direct and error-free measure. However, for several reasons it is likely to be a better measure than wages, which has been used as a proxy for job quality in many previous studies (e.g. Cornelißen (2009) $)^{5}$.

First, job satisfaction is a more general measure than wages, because it not only includes satisfaction with the wage, but also satisfaction with non-monetary characteristics of the job.

Therefore, job satisfaction is more systematically tied to the true job quality.

Second, wages are one of the few job characteristics that can be observed and agreed upon ex ante. Hence, learning is less likely to occur when it comes to wages, but learning might occur for other non-wage characteristics of the job. Hence, taking wages as a measure for job quality is likely to overstate (understate) the relative importance of the stepping-stone (learning) model.

In general, the patterns in wages and job satisfaction are not too far apart in the data (more details on the data see Section 3.1). Following a job quit about 17 percent of the 
individuals experiences a drop in job satisfaction, whereas 51 percent experiences a gain in job satisfaction. When looking at real hourly wages, both these shares are higher: 23 and 62 , respectively ${ }^{6}$.

This implies that for some of the individuals who experience a wage gain the job as a whole is not evaluated as being better. Similarly, for some individuals with a wage loss the total match is not evaluated as being worse. For the reasons mentioned above, this paper will use self-reported job satisfaction as a measure for job quality.

\subsubsection{Approach}

The models presented in Sections 2.1 and 2.2 provide some testable predictions. First, both models predict that in expected terms job quality in the new job exceeds that in the old job (see Equation (4)). Empirical support for this first prediction is found by investigating the effect of job quits on self-reported job satisfaction. Second, although on average match quality increases in both models following a job quit, the probability of facing unexpectedly low quality only exists in the learning model. To test the validity of the learning model in the data, the probability of experiencing a loss in job satisfaction in the years after a job quit is also studied. The results show both models appear to have some empirical validity in the data.

Though both models represent either ends of a continuum of ex ante observable job quality, reality might be somewhere in the middle. Workers may search for jobs in a situation where some information about job quality might be available ex ante but not all; full information will be revealed while the worker is in the job. In the last - and most important - part of this paper testable predictions from both theoretical models concerning the variance in match quality in the new job are used to investigate the relative empirical content of the stepping stone and the learning model. Both models differ in their predictions concerning the variance in match quality in the new job. Hence, changes in job satisfaction following a job quit are the main source of information about the extent to which workers can observe job quality ex ante.

From Equation (5) it is clear that, according to the stepping stone model, satisfaction in a new job after a job quit is always at least as high as job satisfaction in the current job $k$. For example, if satisfaction is measured on a 7-point scale, a worker who is very unsatisfied in his current job $\left(J S^{k}=1\right)$ has a low reservation utility and will accept any job offer he receives $\left(J S^{k+1}=1, \ldots, 7\right)$, while a rather satisfied worker $\left(J S^{k}=6\right)$ will only accept a job offer which will yield a job satisfaction level equal to 6 or higher $\left(J S^{k+1} \geq\right.$ 6). As a result, the expected variance in job satisfaction in the new job for workers who used to be in a poor quality job is larger than the expected variance in job satisfaction in the new job for workers who used to be in a better quality job, hence $\operatorname{Var}_{S S}\left(J S^{k+1}\right.$ | $\left.J S^{k}=\underline{r}\right)>\operatorname{Var}_{S S}\left(J S^{k+1} \mid J S^{k}=\bar{r}\right)$ for each $\underline{r}<\bar{r}$.

Alternatively, in the learning model the true quality of the new job is unknown ex ante and is a random draw from the job offer distribution. As a result, even though in expected terms new job satisfaction is higher than job satisfaction in the current job, job satisfaction in the current job is unrelated to job satisfaction in the new job. As a result, in the learning model the variance of job satisfaction in new, accepted job offers is a constant regardless of current job quality $\left(\operatorname{Var}_{L M}\right)$, while it is decreasing with job satisfaction in the current job according to the stepping stone approach, i.e. $\operatorname{Var}_{L M} \geq \operatorname{Var}_{S S}\left(J S^{k+1} \mid J S^{k}=\underline{r}\right)>$ $\operatorname{Var}_{S S}\left(J S^{k+1} \mid J S^{k}=\bar{r}\right) \forall \underline{r}<\bar{r}$. 
The importance of both models in actual job quit behavior is tested by relating actual variance in job satisfaction in accepted jobs to the variance that would be expected according to both models. I calculate the expected variances in job satisfaction for both models (VarsS and $\operatorname{Var}_{L M}$ ) using the satisfaction distribution among job offers (see Section 4.2 for more details). The actual variance in job satisfaction in accepted job offers $\operatorname{Var}\left(J S^{k+1}\right)$ is taken from the data and used to calculate a weight $s$ such that $\operatorname{Var}\left(J S^{k+1}\right)=s * \operatorname{Var}_{S S}\left(J S^{k+1}\right)+(1-s) * \operatorname{Var}_{L M}$. This $s$ is interpreted as the relative importance of the stepping stone model. When $s=1$ the stepping stone model perfectly explains quit behavior in the labor market, when $s=0$ the learning model is the driving force of job quits. All values of $s$ between 0 and 1 imply that actual job quit behavior is characterized by elements of both models. The larger $s$, the more effective is labor policy aimed at improving labor market outcomes through increased labor mobility.

\section{Data description}

\subsection{Data}

The analyses in this paper are based on information from the British Household Panel Survey (BHPS) for the period 1991-2008. The BHPS collects data annually from a representative sample of approximately 16000 individuals from 9000 households. The dataset contains extensive information on labor market positions and transitions, individual and household income, and other job-related characteristics. The analyses are restricted to working-age male workers, as these workers usually have a strong labor force attachment and job changes for this group most likely serve as a means to improve their employment match $^{7}$.

The wave 1 data were collected in late 1991 - early 1992, the wave 2 data were collected in late 1992 - early 1993, etc. Information on all individual labor market spells that fall between two interview dates is also collected. For each spell information is available on the spell start and end date, as well as the reason for terminating the spell. Workers may report to have terminated the spell for several reasons: promoted, left intentionally, made redundant, dismissed, temporary job ended, took retirement, stopped for health reasons, look after family, care of other person, moved away, started college/university, or left for another reason. This detailed information allows me to pin down job quit behavior. The ending of an employment spell is denoted as a quit if the worker has experienced a jobto-job change from one year to another and reported to have left intentionally ${ }^{8}$. About 28 percent of all employment spells end for this reason ${ }^{9}$. Note that job and worker characteristics are only observed for spells that are active on the day of the interview. Therefore, only these spells can be used in the analysis. However, all quits within two interviews are used to determine whether someone had quit multiple times within the survey year. The sample consists of working-age men who had only one quit per year, such that I can compare the quality of the previous job to the quality of the preceding job. Note that the results found in the paper do not change if I include individuals with multiple quits within the survey year, even though for them I can only compare the quality of the previous job with the quality of the (second/third/etc.) new job at the next interview date. Also, including individuals who experience short unemployment or inactivity spells (i.e. less than 3 months) between two jobs does not affect the findings.

Job satisfaction is reported once a year in each wave, and follows a 1 (not satisfied at all) to 7 (completely satisfied) scale. Table 1 presents the distribution of self-reported job 
Table 1 Job satisfaction distribution (row \%)

\begin{tabular}{|c|c|c|c|c|c|c|c|c|}
\hline \multicolumn{9}{|c|}{ Job satisfaction level } \\
\hline & 1 & 2 & 3 & 4 & 5 & 6 & 7 & $\begin{array}{l}\text { Average job } \\
\text { satisfaction }\end{array}$ \\
\hline \multicolumn{9}{|l|}{ Job status } \\
\hline Stay & 1.6 & 3.2 & 7.8 & 9.9 & 24.8 & 43.2 & 9.6 & 5.2 \\
\hline Quit & 0.7 & 1.7 & 4.3 & 6.3 & 20.1 & 51.7 & 15.4 & 5.6 \\
\hline Layoff & 3.2 & 3.0 & 8.5 & 10.6 & 23.4 & 41.8 & 9.6 & 5.1 \\
\hline Promotion & 0.6 & 1.6 & 6.0 & 6.1 & 25.6 & 51.0 & 9.1 & 5.4 \\
\hline \multicolumn{9}{|l|}{ Tenure } \\
\hline$<2$ years & 2.0 & 3.5 & 7.8 & 9.3 & 23.7 & 43.0 & 10.6 & 5.2 \\
\hline$\geq 2$ years & 1.4 & 2.7 & 7.1 & 9.6 & 24.5 & 44.3 & 10.4 & 5.3 \\
\hline \multicolumn{9}{|l|}{ Working hours } \\
\hline$<30$ hours & 1.2 & 2.2 & 5.2 & 7.5 & 19.9 & 43.4 & 20.6 & 5.6 \\
\hline$\geq 30$ hours & 1.7 & 3.2 & 7.6 & 9.6 & 24.4 & 43.7 & 9.8 & 5.2 \\
\hline \multicolumn{9}{|l|}{ Education level } \\
\hline No education & 2.7 & 3.4 & 5.7 & 9.6 & 20.2 & 39.4 & 19.0 & 5.4 \\
\hline Low education & 2.8 & 3.2 & 5.5 & 11.7 & 21.0 & 39.6 & 16.3 & 5.3 \\
\hline Med education & 1.6 & 2.9 & 7.5 & 10.1 & 25.6 & 42.5 & 9.9 & 5.2 \\
\hline High education & 1.3 & 3.2 & 8.2 & 8.7 & 24.6 & 46.1 & 8.1 & 5.2 \\
\hline \multicolumn{9}{|l|}{ Health status } \\
\hline Poor & 4.4 & 5.9 & 11.1 & 12.3 & 24.6 & 32.7 & 9.1 & 4.8 \\
\hline Fair & 2.6 & 4.4 & 9.6 & 11.9 & 26.5 & 36.8 & 8.2 & 5.0 \\
\hline Good & 1.4 & 3.0 & 7.5 & 9.8 & 25.3 & 44.3 & 8.8 & 5.2 \\
\hline Excellent & 1.4 & 2.2 & 5.9 & 7.2 & 20.7 & 47.6 & 15.0 & 5.5 \\
\hline \multicolumn{9}{|l|}{ Real hourly wage } \\
\hline$\leq \mathrm{p} 25$ & 2.5 & 3.7 & 6.9 & 10.5 & 21.9 & 38.3 & 16.3 & 5.3 \\
\hline p25 - p50 & 2.7 & 3.6 & 8.5 & 10.6 & 24.0 & 39.1 & 11.5 & 5.1 \\
\hline p50 - p75 & 1.6 & 3.1 & 7.7 & 10.1 & 25.1 & 43.8 & 8.5 & 5.2 \\
\hline$\geq p 75$ & 0.7 & 2.4 & 6.8 & 7.6 & 24.6 & 49.5 & 8.6 & 5.4 \\
\hline Allmen & 1.7 & 3.1 & 7.5 & 9.5 & 24.1 & 43.7 & 10.5 & 5.2 \\
\hline
\end{tabular}

Note: Job satisfaction is measured in the year after the characteristics mentioned in the first column have realized. Note that job stayers here refer to individuals who have not left their job in the past year; they may however change jobs in later years.

Source: BHPS.

satisfaction for workers with different characteristics. Though the distribution of job satisfaction is very skewed for all types of workers, fulltime working men and workers in poor health report slightly lower levels of job satisfaction. Furthermore, quitters are more satisfied in their new job compared to individuals who do not change jobs (i.e. stayers). Finally, people in the top quarter of the wage distribution do not seem to report higher levels of job satisfaction than those in the lower part of the wage distribution.

\subsection{Descriptive figures}

A first step in investigating job search and quit behavior involves looking at the course of job satisfaction in the years before and after the job change has occurred. Figure 1 illustrates how average job satisfaction levels differ across job quitters and job stayers. As is 


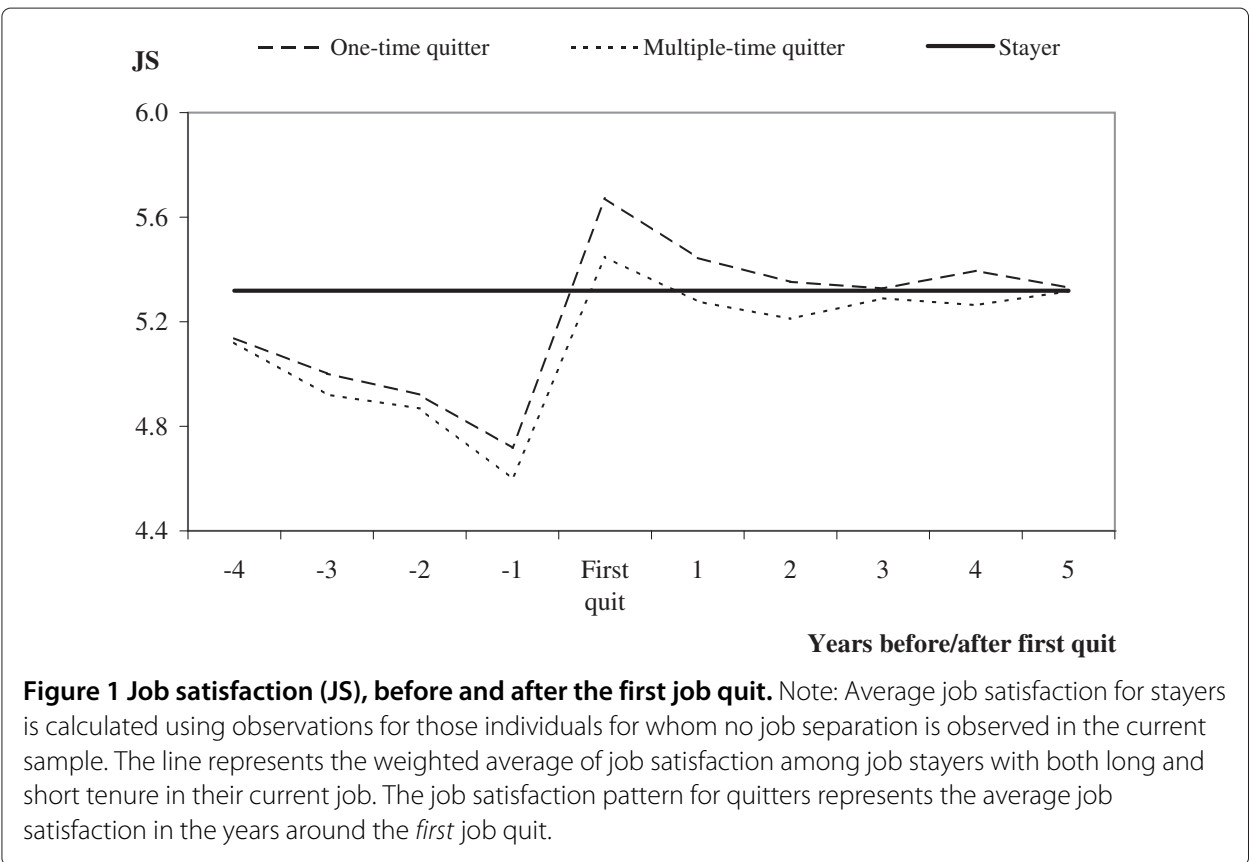

clear from the figure, job satisfaction not only dips in the year prior to the first quit, but is also significantly lower (compared to job stayers) in the years before. This can be a reason for workers to start looking for another job ${ }^{10}$. People who are only observed to quit once (one-time quitters) obtain an increase in their job satisfaction at the time of the job change, which is in line with the predictions from both theoretical models. Despite the small decrease in job satisfaction after the first year in the new job, a job quit implies a permanent increase in job satisfaction up to the level of job stayers. Note that the decline after the first year is an average decline: about 35 percent of the workers experience a decline in job satisfaction after the first year, for 48 percent of the workers job satisfaction remains unchanged while for 17 percent it increases after the first year. This variation provides some preliminary evidence for the learning model. For people who quit several times during the observation period (multiple-time quitters), the situation is slightly different in two respects. First, job satisfaction in the years before the job quit as well as the peak at the time of the job quit is lower than for one-time quitters ${ }^{11}$. Possibly, repeated mobility can be explained by the fact that these workers come from relatively bad matches, and they need several job changes to catch up with workers who are satisfied with their job. This stepping stone hypothesis seems to be confirmed in Table 2, which illustrates that not only the probability to quit, but also that the probability of having a future quit, is a decreasing function of the satisfaction level in the year before the first job quit. The table also illustrates the importance of multiple-quit behavior: while 75 percent of the workers do not quit at all, 38 percent of the workers who do quit are observed to quit multiple times. Second, Figure 1 shows that for multiple-time quitters their level of job satisfaction falls back to a level below that of job stayers within a year after the first job quit. This might provide another explanation for their repeated job change behavior ${ }^{12}$. All in all, the descriptive evidence in this section seems to confirm the role of both the stepping stone hypothesis and the learning approach in explaining repeated job quits. 
Table 2 Frequency of job quits, by initial level of job satisfaction (row percentages [No. of persons])

\begin{tabular}{|c|c|c|c|c|c|c|}
\hline & \multicolumn{4}{|c|}{ Total number of quits observed } & \multirow[b]{2}{*}{ Total } & \multirow{2}{*}{$\begin{array}{c}\text { Prob. of } \\
\text { having } \\
\text { multiple quits (\%) }\end{array}$} \\
\hline & 0 & 1 & 2 & 3 or more & & \\
\hline \multicolumn{7}{|l|}{$\begin{array}{l}\text { Job satisfaction in } \\
\text { year before first quit* }\end{array}$} \\
\hline 1 & 20.2 & 53.9 & 14.6 & 11.2 & $\begin{array}{l}100.0 \\
{[89]}\end{array}$ & 25.9 \\
\hline 2 & 20.2 & 47.0 & 18.6 & 14.2 & $\begin{array}{l}100.0 \\
{[183]}\end{array}$ & 32.8 \\
\hline 3 & 47.0 & 32.5 & 13.4 & 7.2 & $\begin{array}{l}100.0 \\
{[419]}\end{array}$ & 20.5 \\
\hline 4 & 73.9 & 15.3 & 5.6 & 5.2 & $\begin{array}{l}100.0 \\
{[972]}\end{array}$ & 10.8 \\
\hline 5 & 77.8 & 13.9 & 4.8 & 3.5 & $\begin{array}{c}100.0 \\
{[2359]}\end{array}$ & 8.3 \\
\hline 6 & 80.2 & 12.4 & 4.2 & 3.2 & $\begin{array}{c}100.0 \\
{[3368]}\end{array}$ & 7.4 \\
\hline 7 & 79.0 & 13.8 & 2.5 & 4.7 & $\begin{array}{l}100.0 \\
{[792]}\end{array}$ & 7.2 \\
\hline Total & $\begin{array}{c}75.0 \\
{[6134]}\end{array}$ & $\begin{array}{c}15.6 \\
{[1273]}\end{array}$ & $\begin{array}{c}5.3 \\
{[431]}\end{array}$ & $\begin{array}{c}4.2 \\
{[344]}\end{array}$ & $\begin{array}{c}100.0 \\
{[8182]}\end{array}$ & 9.5 \\
\hline No. of observations & 24824 & 8133 & 3403 & 3396 & 39756 & \\
\hline
\end{tabular}

*For job stayers this refers to average job satisfaction during their (observed) working life. Source: BHPS.

\section{Empirical results}

\subsection{Job satisfaction}

Before investigating the relative importance of both theoretical models in the data (next section), this section first checks whether the data actually fit the main predictions from both models. First, the prediction that average match quality increases after a job quit is tested. This section investigates job satisfaction immediately after a job quit by estimating the fixed effects ordered logit model developed in Ferrer-i Carbonell and Frijters (2004):

$$
J S_{i t}^{*}=Q_{i t} \beta_{1}+Z_{i t} \beta_{2}+\alpha_{i}+\varepsilon_{i t} \quad \text { with } \quad J S_{i t}=j \Leftrightarrow J S_{i t}^{*} \in\left[\gamma_{i j}, \gamma_{i, j+1}\right\rangle
$$

where $J S_{i t}^{*}$ is latent job satisfaction, $J S_{i t}$ is observed satisfaction, $\gamma_{i j}$ is the individual threshold level (increasing in $j$ ) for job satisfaction, $Q$ equals 1 if someone has quit his job in the past year (the actual timing of which can vary from one day ago up to a year), $Z$ is a vector of worker and job characteristics and $\varepsilon$ is a time-varying logit-distributed error term. Note that job satisfaction is a subjective measure and individual-specific characteristics may cause some workers always to report lower satisfaction scores than others while they are in fact equally satisfied (e.g. due to a different interpretation of the satisfaction scale). The parameter $\alpha_{i}$ controls for such unobserved time-invariant individual effects. By introducing individual specific cut-off points $c_{i}=\sum_{t} J S_{i t} / n_{i}$, where $n$ is the number of observations per individual, Ferrer-i Carbonell and Frijters (2004) show that the fixed effects ordered logit model can be reformulated as a fixed effects binomial logit model ${ }^{13}$. Applying Chamberlain's method (1980) removes the individual specific effects $\alpha_{i}$ and the individual specific thresholds $\gamma_{i}$ from the likelihood specification. The fixed effects logit 
model is estimated over observations $y_{i t}$, where $y_{i t}=1$ if $J S_{i t} \geq c_{i}$ and 0 otherwise ${ }^{14}$. The results are presented in part I of Table 3. From Panel A it appears that job satisfaction increases substantially after a job quit ${ }^{15}$. Hence, on average, quits serve to form better matches, which confirms the prediction of both models ${ }^{16}$. In order to take into account the repeated character of job quits, panel B includes the number of previous quits the worker has experienced sofar ${ }^{17}$. The results show that changing jobs serves to find a better match, but the average marginal gain decreases with the number of previous quits. As a result, workers may decide to stay in their job if the expected gains from quitting no longer exceed the mobility costs.

Second, in order to test the predictions regarding (unexpected) drops in new match quality, Part II studies the probability of a reduction in job satisfaction from one year to the other. Although both the stepping stone and the learning model predict an average gain in job satisfaction following a job quit, in the stepping stone model this is the result from only positive changes in job satisfaction, while in the learning model this is a positive sum of all positive and negative changes in job satisfaction. Hence, to distinguish between both models it is necessary that some workers quitting their job experience a decline in job satisfaction. The results from a fixed effects logit model are presented in the lower part of Table 3 . The results indicate that job quitters are less likely to experience a reduction in job satisfaction than job stayers. Furthermore, a reduction in job satisfaction is more likely if workers leave a good job. This confirms earlier evidence from the raw data that job satisfaction reductions occur after a job quit, which means that there is a role for the learning model. The relative importance of both models is investigated in the next section.

\subsection{Decomposing job satisfaction variance}

The evidence thus far indicates that repeated job quit behavior can be characterized both by stepping stone and learning elements. Since the stepping stone model and the learning

Table 3 Job satisfaction after a job quit

\begin{tabular}{|c|c|}
\hline I. JS $t$ - FIXED EFFECTS ORDERED LOGIT RESULTS & \\
\hline \multicolumn{2}{|l|}{ A. Baseline } \\
\hline Q & $0.705(0.051)^{* *}$ \\
\hline \multicolumn{2}{|c|}{$\log L=-15700.81$} \\
\hline \multicolumn{2}{|l|}{ B. Including total number of quits sofar } \\
\hline Q & $0.745(0.088)^{* *}$ \\
\hline Total number of quits & $0.312(0.028)^{* *}$ \\
\hline$Q *$ Total number of quits & $-0.090(0.043)^{* *}$ \\
\hline \multicolumn{2}{|c|}{$\log L=-15637.32$} \\
\hline \multicolumn{2}{|l|}{ II. P(JS $\left.t_{t}<J S_{t-1}\right)$ - FIXED EFFECTS LOGIT RESULTS } \\
\hline Q & $-1.621(0.385)^{* *}$ \\
\hline$J S_{t-1}$ & $1.304(0.022)^{* *}$ \\
\hline$Q * J S_{t-1}$ & $0.185(0.067)^{* *}$ \\
\hline
\end{tabular}

Note: Dependent variable is job satisfaction $\left(J S_{t} ; 1-7\right)$ in Part I and the probability of a reduction in job satisfaction

$\left(P\left(J S_{t}<J S_{t-1}\right)\right)$ in Part II. Other explanatory variables included in the estimation are tenure and its squared value, age and its squared value, log of hours worked, log of hourly wage, and dummies for marital status, education level, industry, occupation, firm size, health, temporary job, and calendar year; standard errors in parentheses; ${ }^{* *}\left({ }^{*}\right)$ indicates that the coefficient is different from zero at a 5\% (10\%) level of significance. Analysis is based on 35242 observations.

Source: BHPS. 
model represent both ends of a continuum of ex ante observable job quality, in this section I investigate the relative empirical content of the theoretical approaches by decomposing the variance in job satisfaction in newly accepted jobs. Note that the predictions concerning this variance are the main distinction between both models (see also Section 2.3.2). When mobility costs are assumed to be nonexistent, in the stepping stone model workers are expected to accept any job which offers them at least the satisfaction level that they currently experience in their job. As a result, expected variance in satisfaction of accepted job offers will be decreasing with the initial level of job satisfaction. Alternatively, in the learning approach workers accept a job which is expected to offer a higher satisfaction level than they currently experience in their job. However, since job quality in the new job is a random draw and unobservable ex ante the new quality may well be worse and hence the expected variance is independent of job quality in the current job ${ }^{18}$.

The expected variance in job satisfaction in a newly accepted job $k+1$ given the quality of the current job $\left(J S^{k}\right)$ can hence be calculated as follows:

Stepping stone: $\operatorname{Var}\left\{\mathrm{E}\left(J S^{k+1} \mid J S^{k}=R\right)\right\}=\sum_{r=R}^{7}\left(J S_{r}^{k+1}-\sum_{r=R}^{7} \frac{p_{r}}{\sum_{r=R}^{7} p_{r}} J S_{r}^{k+1}\right)^{2} \frac{p_{r}}{\sum_{r=R}^{7} p_{r}}$

Learning model:Var $\left\{\mathrm{E}\left(J S^{k+1} \mid J S^{k}=R\right)\right\}=\sum_{r=1}^{7}\left(J S_{r}^{k+1}-\sum_{r=1}^{7} \frac{p_{r}}{\sum_{r=1}^{7} p_{r}} J S_{r}^{k+1}\right)^{2} \frac{p_{r}}{\sum_{r=1}^{7} p_{r}}$

where $p_{r}$ represents the probability of receiving a job offer with satisfaction level equal to $r$, with $R=1, \ldots, 7$ and $r=1, \ldots, 7$. Note that the variance in Equation (7) is decreasing in the level of job satisfaction in the current job, while that in Equation (8) is independent of the current job satisfaction level.

In order to calculate $p_{r}$ information about the job offer distribution is needed. However, in the data I only observe whether workers accepted a new job rather than whether they have been offered one. Therefore, the distribution of accepted jobs has to be exploited to find an approximation for the offered job distribution. I take the satisfaction distribution of new jobs accepted by labor market entrants who have just left school, because these workers are expected to accept any job offer they receive ${ }^{19}$. Note that this distribution refers to the accepted job offer distribution, which might deviate from the true job offer distribution if workers can observe job quality ex ante and hence can pick the best of multiple job offers. This observed distribution of accepted job offers is presented in Figure 2. I use this distribution to calculate the expected variance following the stepping stone model and plot this distribution together with the actual variance observed in job satisfaction in new jobs among job quitters in Figure 3.

In a next step, the expected variance following the learning model needs to be calculated. The theoretical model predicts that the expected variances following the stepping stone and the learning model should be the same at $J S^{k}=1$ if individuals receive one job offer at the time. However, the variances can be different if individuals receive multiple offers at a given point in time: in the stepping stone model they can pick the best offer, in the learning model they cannot distinguish which is the best offer. From Figure 3 it can 


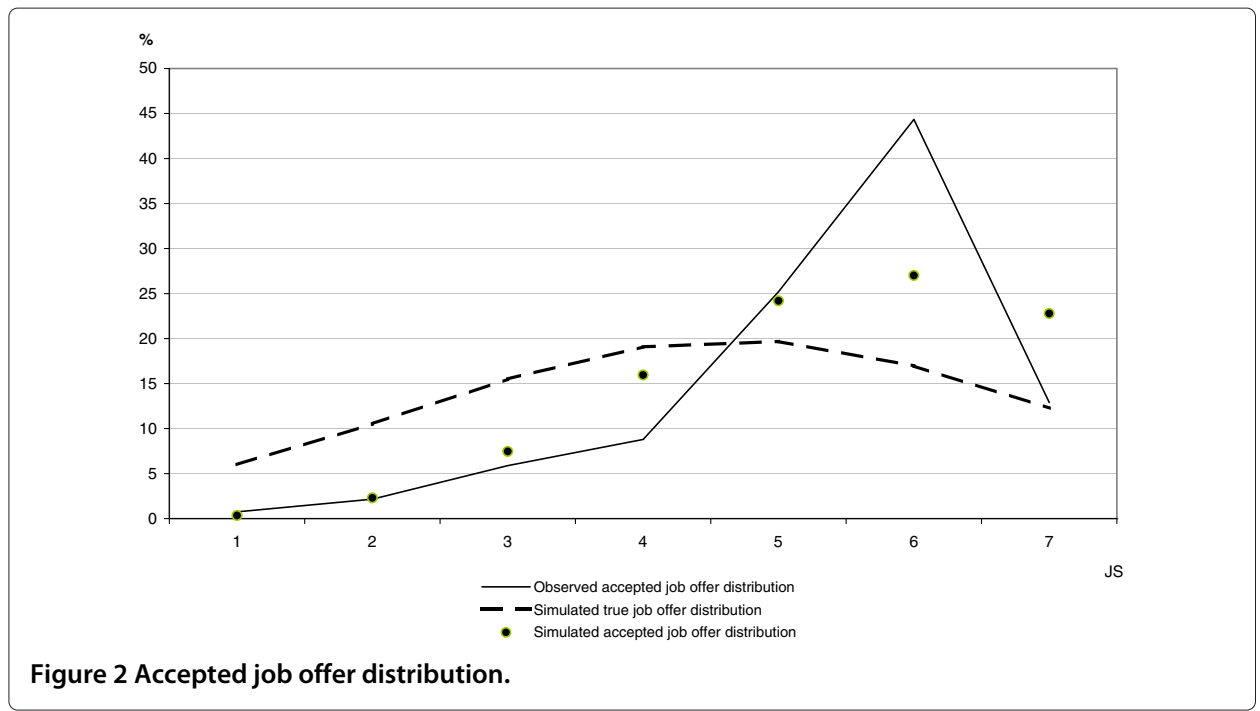

be seen that it is a likely assumption that individuals receive multiple job offers in a certain time interval, since the model cannot explain the actual variance in satisfaction in the new job for $J S^{k}=1$ if both expected variances are the same (because the actual variance at $J S^{k}=1$ is higher; 2.28 versus 1.43). This also explains the high number of "good" offers in the observed accepted job satisfaction distribution from Figure 2. Hence, in order to calculate the expected variance for the learning model, where the underlying assumption is that ex ante job quality is not observable, we need to infer the true job offer distribution (i.e. including those offers which were worse than the offer that was accepted) that underlies the observed accepted job offer distribution among labor market entrants. This can easily be done using an optimization program (e.g. in MATLAB) that simulates the true job offer distribution and the true number of job offers that people receive in a certain period such that the combination of both - given the assumption that people can pick the best available offer - would lead to a simulated accepted job offer distribution, which best approximates the observed accepted job offer distribution in Figure $2^{20}$. As can be seen in Figure 2 the simulated accepted job offer distribution, which has a mean

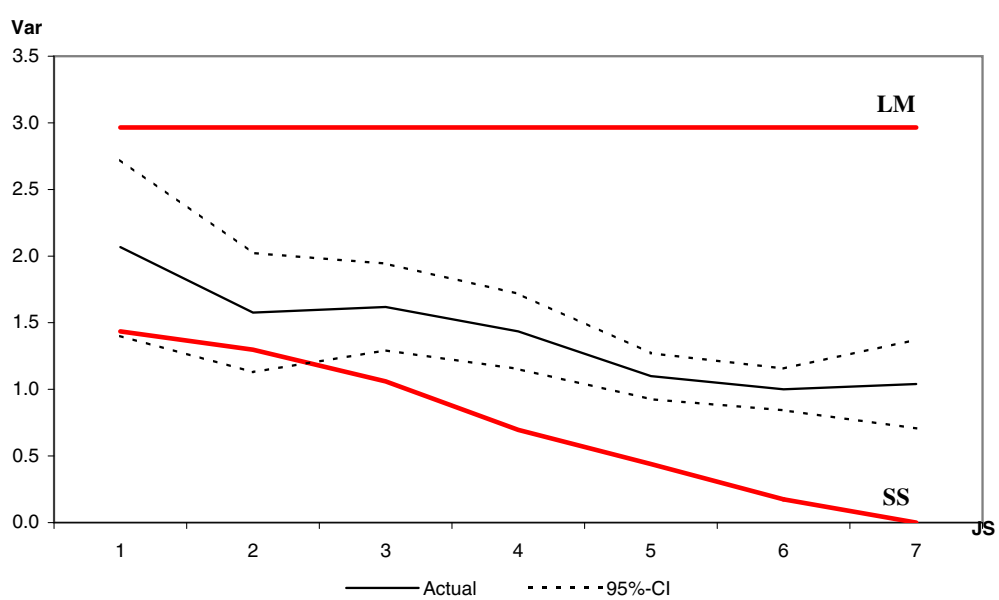

Figure 3 Variance in job satisfaction in accepted job. 
of 4.67 and a standard deviation of 2.37, makes a rather good fit to the observed distribution of accepted job offers. This is based on the simulated number of offers each person receives in a period being equal to two. Now, the simulated true job offer distribution is used to calculate the expected variance following the learning model, which is presented in Figure 3. Since the stepping stone model and the learning model represent both ends of a continuum, it is not surprising to find the actual variance in Figure 3 to be in between both extreme variance predictions.

Table 4 presents a decomposition of the actual variance in job satisfaction among job quitters using the expected variances for the stepping stone and learning model. In particular, it shows the share $s$ of the variance in actual job satisfaction in accepted new jobs that can be explained by the stepping stone theory ${ }^{21}$ :

$$
s=\frac{\operatorname{Var}-\operatorname{Var}(L M)}{\operatorname{Var}(S S)-\operatorname{Var}(L M)}
$$

where $\operatorname{Var}, \operatorname{Var}(L M)$, and $\operatorname{Var}(S S)$ represent the actual variance (observed in the data) and the expected variance following the learning model and stepping stone model, respectively. The share $s$ and its standard error are obtained from a non-parametric bootstrap with 5000 replications, which is used to calculate Var. From Panel A it appears that close to 70 percent of the job quits arises from a stepping stone motive ${ }^{22}$. This implies that

Table 4 Variance decomposition - proportion explained by stepping stone theory

\begin{tabular}{|c|c|c|c|c|c|c|c|c|}
\hline \multicolumn{9}{|c|}{ Job satisfaction in old job: } \\
\hline & 1 & 2 & 3 & 4 & 5 & 6 & 7 & Average \\
\hline \multicolumn{9}{|c|}{ A. Baseline } \\
\hline \multicolumn{9}{|c|}{ Multiple time job } \\
\hline & $0.572^{* *}$ & $0.828^{* *}$ & $0.704^{* *}$ & $0.672^{* *}$ & $0.738^{* *}$ & $0.704^{* *}$ & $0.648^{* *}$ & $0.695^{* *}$ \\
\hline & $(0.220)$ & $(0.138)$ & $(0.087)$ & $(0.064)$ & $(0.035)$ & $(0.029)$ & $(0.058)$ & $(0.042)$ \\
\hline $\mathbf{N}$ & 91 & 187 & 316 & 355 & 765 & 1034 & 245 & \\
\hline \multicolumn{9}{|c|}{ B. JS for new hires from unemployment } \\
\hline & $1.018^{* *}$ & $1.042^{* *}$ & $0.823^{* *}$ & $0.761^{* *}$ & $0.787^{* *}$ & $0.752^{* *}$ & $0.697^{* *}$ & $0.840^{* *}$ \\
\hline & $(0.260)$ & $(0.126)$ & $(0.076)$ & $(0.053)$ & $(0.029)$ & $(0.024)$ & $(0.049)$ & $(0.044)$ \\
\hline \multicolumn{9}{|c|}{ C. Ordinal variation measure } \\
\hline & $0.713^{* *}$ & $0.869^{* *}$ & $0.767^{* *}$ & $0.701^{* *}$ & $0.746^{* *}$ & $0.687^{* *}$ & $0.591^{* *}$ & $0.723^{* *}$ \\
\hline & $(0.153)$ & $(0.104)$ & $(0.067)$ & $(0.051)$ & $(0.0293)$ & $(0.022)$ & $(0.037)$ & $(0.030)$ \\
\hline \multicolumn{9}{|c|}{ D. JS in final year of new job } \\
\hline & $0.790^{* *}$ & $0.561^{* *}$ & $0.858^{* *}$ & $0.700^{* *}$ & $0.773^{* *}$ & $0.727^{* *}$ & $0.498^{* *}$ & $0.701^{* *}$ \\
\hline & $(0.191)$ & $(0.145)$ & $(0.072)$ & $(0.061)$ & $(0.030)$ & $(0.024)$ & $(0.076)$ & $(0.039)$ \\
\hline \multicolumn{9}{|c|}{ E. Conditioning on wage and hours worked } \\
\hline & $0.465^{*}$ & $0.809^{* *}$ & $0.667^{* *}$ & $0.666^{* *}$ & $0.698^{* *}$ & $0.647^{* *}$ & $0.616^{* *}$ & $0.652^{* *}$ \\
\hline & $(0.248)$ & $(0.130)$ & $(0.087)$ & $(0.063)$ & $(0.037)$ & $(0.033)$ & $(0.066)$ & $(0.045)$ \\
\hline
\end{tabular}

Note: The proportion explained by the stepping stone theory is computed as follows: $s=(\operatorname{Var}-\operatorname{Var}(L M)) /(\operatorname{Var}(S S)-\operatorname{Var}(L M))$ where $\operatorname{Var}, \operatorname{Var}(L M)$ and $\operatorname{Var}(S S)$ represent actual variance and expected variance according to the learning model and the stepping stone theory, respectively. Standard errors calculated using a non-parametric bootstrap with 5000 replications are in parentheses; a $^{* *}\left(^{*}\right)$ indicates that the coefficient is different from zero at a $5 \%(10 \%)$ level of significance.

Source: BHPS. 
labor policies aimed at improving labor market outcomes through stimulated job mobility can be quite effective. As part of a sensitivity analysis, Panel B replicates the results using an alternative accepted job offer distribution. Because labor market entrants lack any labor market experience they may receive relatively more poor job offers and hence low job offers may be over-represented in the accepted job offer distribution. Alternatively, labor market entrants may have started their job search well before the end of their studies and hence could have acted more selectively than other workers. Therefore, Panel B uses the distribution of accepted job offers by those workers who were hired from unemployment. These workers are also expected to accept any job offer (as suggested by Christensen et al. (2005)) and the results show that the importance of the stepping stone model is somewhat higher here ${ }^{23}$. As part of a sensitivity analysis, Panel C takes into account the ordinal nature of the job satisfaction variable. That is, because satisfaction is not a cardinal variable, the variance may not be the best measure of dispersion, because it imposes a supraordinal assumption about the nature of the continuum underlying the different categories (Blair and Lacy (2000)). Therefore, in Panel C I use an index for ordinal variation based on Berry and Mielke (1992) to calculate $s$. It appears that the results are not much different from those in Panel A.

The role of the stepping stone model might be overrated in Panels A to C for several reasons. First, if mobility costs are existent and positive, workers will only accept a new job if it yields a strictly higher utility than the current job $^{24}$. As a result, variance resulting from workers accepting a new job of the same quality as the previous job will no longer be attributed to the stepping stone model but to the learning model. Though for unsatisfied workers this will happen rarely (up to 6 percent of the cases), satisfied workers are much more likely to accept a new job with similar job satisfaction rating (about 50 percent of the cases). As a result, the shares presented in Panels $A$ to $C$ should be considered as an upper bound. Alternatively, the importance of the stepping stone model might be misstated if workers have not completely learned the true job quality during the first year in the job, because Panels A to C relate job satisfaction in the old job to job satisfaction reported in the first year of the new job. Therefore, in Panel D, I use job satisfaction reported in the final year of the new job when learning is expected to be completed ${ }^{25}$. Note that the share of variance attributed to the stepping stone model is similar. Alternatively, the importance of learning could be overstated if individuals answer differently to job satisfaction questions in different waves (which could occur for example if they happen to be in a very bad mood when filling in the questionnaire). Finally, in Panel E I look at job satisfaction while conditioning on wages and hours worked. After running a job satisfaction estimation (similar to the one presented in Table 3), one can predict what job satisfaction in the new job would have been if the real hourly wage and the number of working would have been the same as in the old job. Since wages and working hours are usually job characteristics that are observable ex-ante, it is not surprising that the role of the stepping stone theory is smaller once you condition on having no change in these job characteristics. Nevertheless, the results are not very different from the results in Panel A.

Table 5 presents some sensitivity results for different subgroups of workers, where Panel A replicates the baseline results from the previous table. Panel B shows that quit behavior by workers who quit only once (single time quitters) is characterized by more stepping stone features than for those who quit several times during the observation period. This may explain why the former quit only once. Panel $\mathrm{C}$ illustrates that 
Table 5 Variance decomposition - sensitivity

\begin{tabular}{|c|c|c|c|c|c|c|c|c|}
\hline & \multicolumn{7}{|c|}{ Job satisfaction in old job: } & \multirow[b]{2}{*}{ Average } \\
\hline & 1 & 2 & 3 & 4 & 5 & 6 & 7 & \\
\hline \multicolumn{9}{|c|}{ A. Baseline } \\
\hline & $0.572^{* *}$ & $0.828^{* *}$ & $0.704^{* *}$ & $0.672^{* *}$ & $0.738^{* *}$ & $0.704^{* *}$ & $0.648^{* *}$ & $0.695^{* *}$ \\
\hline & $(0.220)$ & $(0.138)$ & $(0.087)$ & $(0.064)$ & $(0.035)$ & $(0.029)$ & $(0.058)$ & $(0.042)$ \\
\hline \multicolumn{9}{|c|}{ B. Single vs. multiple quits } \\
\hline \multicolumn{9}{|c|}{ Single time job quitters } \\
\hline & $0.870^{* *}$ & $0.884^{* *}$ & $0.822^{* *}$ & $0.540^{* *}$ & $0.781^{* *}$ & $0.711^{* *}$ & $0.707^{* *}$ & $0.759^{* *}$ \\
\hline & $(0.260)$ & $(0.242)$ & $(0.150)$ & $(0.110)$ & $(0.056)$ & $(0.047)$ & $(0.075)$ & $(0.059)$ \\
\hline \multicolumn{9}{|c|}{ Multiple time job quitters } \\
\hline & 0.292 & $0.808^{* *}$ & $0.645^{* *}$ & $0.745^{* *}$ & $0.714^{* *}$ & $0.701^{* *}$ & $0.610^{* *}$ & $0.646^{* *}$ \\
\hline & $(0.340)$ & $(0.160)$ & $(0.110)$ & $(0.074)$ & $(0.045)$ & $(0.035)$ & $(0.081)$ & $(0.059)$ \\
\hline \multicolumn{9}{|c|}{ C. Young vs. older workers } \\
\hline \multicolumn{9}{|l|}{ Age $<30$} \\
\hline & 0.223 & $0.921^{* *}$ & $0.633^{* *}$ & $0.587^{* *}$ & $0.697^{* *}$ & $0.679^{* *}$ & $0.710^{* *}$ & $0.636^{* *}$ \\
\hline & $(0.466)$ & $(0.223)$ & $(0.145)$ & $(0.101)$ & $(0.058)$ & $(0.045)$ & $(0.064)$ & $(0.079)$ \\
\hline \multicolumn{9}{|l|}{ Age $\geq 30$} \\
\hline & $0.742^{* *}$ & $0.782^{* *}$ & $0.759^{* *}$ & $0.731^{* *}$ & $0.768^{* *}$ & $0.725^{* *}$ & $0.590^{* *}$ & $0.728^{* *}$ \\
\hline & $(0.229)$ & $(0.170)$ & $(0.111)$ & $(0.080)$ & $(0.043)$ & $(0.036)$ & $(0.094)$ & $(0.048)$ \\
\hline \multicolumn{9}{|c|}{ D. Low vs. high educated } \\
\hline \multicolumn{9}{|c|}{ Low educated } \\
\hline & $0.792^{* *}$ & $0.648^{* *}$ & $0.718^{* *}$ & $0.695^{* *}$ & $0.732^{* *}$ & $0.700^{* *}$ & $0.733^{* *}$ & $0.717^{* *}$ \\
\hline & $(0.248)$ & $(0.293)$ & $(0.138)$ & $(0.102)$ & $(0.054)$ & $(0.042)$ & $(0.056)$ & $(0.061)$ \\
\hline \multicolumn{9}{|c|}{ High educated } \\
\hline & 0.269 & $0.910^{* *}$ & $0.678^{* *}$ & $0.653^{* *}$ & $0.749 * *$ & $0.700^{* *}$ & $0.564^{* *}$ & $0.646^{* *}$ \\
\hline & $(0.392)$ & $(0.133)$ & $(0.120)$ & $(0.080)$ & $(0.047)$ & $(0.040)$ & $(0.110)$ & $(0.066)$ \\
\hline \multicolumn{9}{|c|}{ E. Occupational change } \\
\hline \multicolumn{9}{|c|}{ Same occupation } \\
\hline & $0.590^{*}$ & $0.864^{* *}$ & $0.533^{* *}$ & $0.742^{* *}$ & $0.771^{* *}$ & $0.723^{* *}$ & $0.728^{* *}$ & $0.707^{* *}$ \\
\hline & $(0.332)$ & $(0.157)$ & $(0.132)$ & $(0.078)$ & $(0.042)$ & $(0.036)$ & $(0.056)$ & $(0.058)$ \\
\hline \multicolumn{9}{|c|}{ New occupation } \\
\hline & $0.515^{*}$ & $0.748^{* *}$ & $0.953^{* *}$ & $0.565^{* *}$ & $0.722^{* *}$ & $0.650^{* *}$ & $0.536^{* *}$ & $0.670^{* *}$ \\
\hline & $(0.308)$ & $(0.227)$ & $(0.103)$ & $(0.105)$ & $(0.060)$ & $(0.050)$ & $(0.126)$ & $(0.063)$ \\
\hline \multicolumn{9}{|c|}{ F. 1990 s vs 2000 s } \\
\hline \multicolumn{9}{|l|}{ 1991-1999 } \\
\hline & 0.082 & $0.628^{* *}$ & $0.594^{* *}$ & $0.619^{* *}$ & $0.722^{* *}$ & $0.673^{* *}$ & $0.741^{* *}$ & $0.580^{* *}$ \\
\hline & $(0.447)$ & $(0.254)$ & $(0.130)$ & $(0.108)$ & $(0.065)$ & $(0.058)$ & $(0.046)$ & $(0.078)$ \\
\hline \multicolumn{9}{|l|}{$2000-2008$} \\
\hline & $0.851^{* *}$ & $0.948^{* *}$ & $0.782^{* *}$ & $0.703^{* *}$ & $0.745^{* *}$ & $0.718^{* *}$ & $0.575^{* *}$ & $0.760^{* *}$ \\
\hline & $(0.209)$ & $(0.155)$ & (0.119) & $(0.077)$ & $(0.041)$ & $(0.032)$ & $(0.096)$ & $(0.046)$ \\
\hline
\end{tabular}

learning is more important early in the career than among older workers. This might be due to the fact that older workers have acquired better networks, therefore they can better observe job quality ex ante. Furthermore, job quit behavior by low educated workers is characterized by more stepping stone features than job quits by high educated workers (Panel D). Possibly, tasks are not as narrowly defined for higher educated and their compensation package contains more non-wage aspects, therefore job quality is more difficult to assess ex ante. Panel E shows that workers who change occupation are less able to identify the quality of the job in the new occupation ex ante 
than people who remain in the same occupation. This may suggest that policy makers should not just aim to stimulate general labor mobility, but rather aim to elicit within-occupation mobility in order to achieve more efficient outcomes. Finally, in the 1990s job quit behavior was characterized by less stepping stone elements than it was in the 2000s. This may have to do with the widespread usage of internet in the latter time period, which has reduced the role of information asymmetries in the job search process. Other sensitivity checks, such as private versus public sector workers, did not yield any significant different results and hence are not presented in the table.

Job satisfaction might not only change due to a job change but may also change from one year to the other because of some exogenous variation such as a reorganization. The presence of such exogenous variation may affect the findings in Tables 4 and 5 . To find evidence for such variation, I investigate the variance in job satisfaction for job stayers from one year to the other. Figure 4 illustrates the variance in job satisfaction for stayers relative to the variance for job quitters. It appears that the variance among dissatisfied workers is much higher among stayers than among job quitters. This suggests that job quitters are able to positively select into good jobs. Hence, the difference in variance, i.e. the area between the two lines, can be seen as the gains from search and changing jobs. Furthermore, note that the 'exogenous' variation among job stayers is not constant across workers. Workers who are very dissatisfied with their job are more likely to experience a change in job satisfaction one year later than those that are quite satisfied already. Possibly, workers look for alternatives and firms are willing to offer different tasks or different fringe benefits to dissatisfied workers in order to retain them with the firm, while such ad hoc offers are less frequently made to workers who are satisfied already ${ }^{26}$. This suggests that there seems to be some stepping stone element even for job stayers. Panel B in Table 6 indeed shows that a job change is not always required to improve job satisfaction. In particular, the difference between stayers and quitters (bottom panel) indicates that there are gains from search only for those workers who are dissatisfied with their job. For those reporting being '(completely) satisfied' the probability of improving job satisfaction within the job and across jobs is similar.

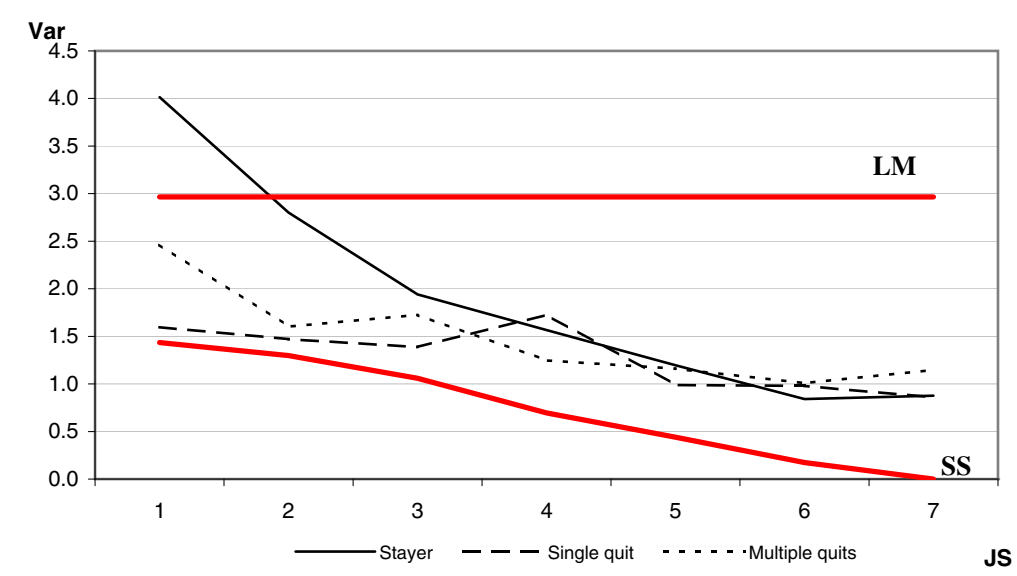

Figure 4 Variance in job satisfaction in accepted job - job stayers vs. quitters. 
Table 6 Variance decomposition - quit vs. stay

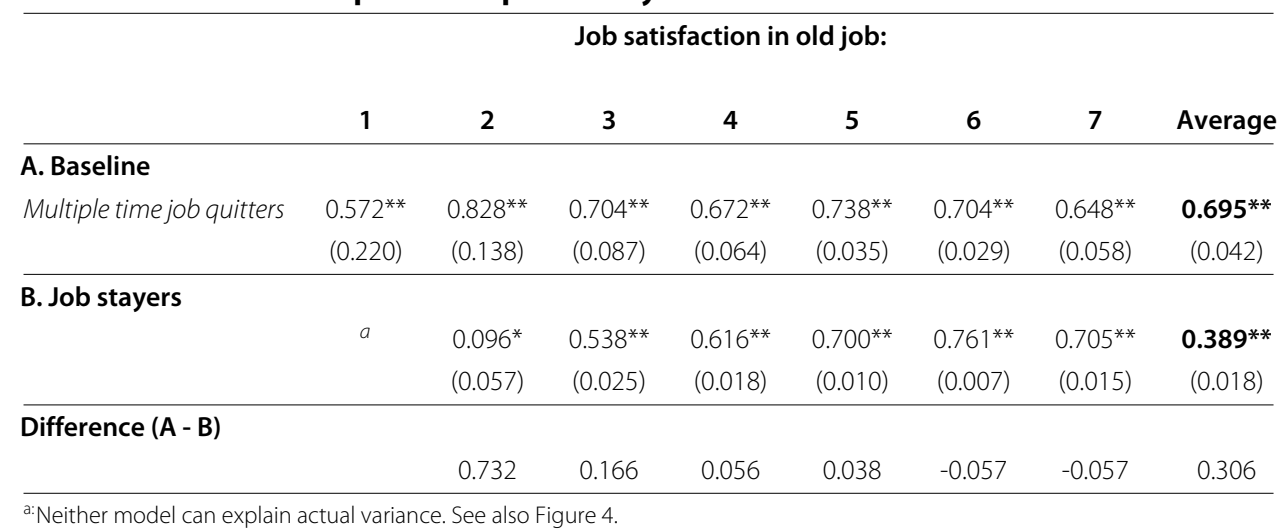

\section{Conclusions}

This paper studies repeated job quit behavior to investigate whether such job changes contribute to better matching efficiency or whether they constitute a relocation of labor without any increase in match quality. This information is crucial for labor market policy, in which increased labor mobility is often an important tool used by policy makers to improve labor market outcomes. Theoretical studies often adopt either the stepping stone model or the learning model as the explanatory mechanism for labor mobility. The main difference between these two is that the former assumes perfect observability of job quality before the job starts and hence only allows for job quality improvements after a job quit, whereas in the latter job quality cannot be assessed ex ante and hence job quality is expected to improve after a job quit but may as well end up being lower. This paper argues that actual job quit behavior is characterized by a mixture of both. Therefore, the main aim of the paper is to investigate the relative empirical content of both models in job quit decisions. The results from a variance decomposition help improve our understanding of job quit behavior, a key phenomenon determining the functioning of the labor market, which is essential for formulating effective labor policy.

Using UK data over the period 1991-2008, the analyzes in this paper show that on average job satisfaction increases with each job quit, though at a decreasing rate. This finding is consistent with both the stepping stone and the learning model. However, the fact that some job quitters experience a reduction in job satisfaction suggests that at least some quits can be explained by the learning model. This paper is the first to quantify the relative empirical content of both models. A decomposition of variance in satisfaction in the new job shows that close to 70 percent of job quits arises from a stepping stone motive. This implies that repeated job quits mainly serve as a stepping stone to more happiness at work and as such may contribute to matching efficiency.

This result indicates that government policy aiming to increase labor mobility can be very effective in improving labor market outcomes. However, the efficacy can be even higher if policy is more specifically targeted to elicit within-occupation job changes, where ex ante information seems more easily observable. Furthermore, there is still room for improvement if policy makers would not only focus on increased job mobility, but also would invest in transparency of labor markets. If workers would be more capable of 
observing job quality ex ante, they can better distinguish good jobs from bad jobs, and job mobility is more likely to improve matching efficiencies.

\section{Endnotes}

${ }^{1}$ Some economists are skeptical about using a self-reported satisfaction measure, because of measurement issues and difficulties in interpersonal comparisons. Recent papers by Blanchflower D (2008) and Oswald and Wu (2009) address a number of those reservations by illustrating the robust findings in the satisfaction literature and how satisfaction is related to more objectively observable measures of wellbeing.

${ }^{2}$ Note that this follows a large psychological literature, where these effects have been investigated before.

${ }^{3}$ Earlier studies such as MacDonald (1988) have extended this baseline framework to allow for e.g. heterogeneous workers and/or firms.

${ }^{4}$ For simplicity, search and mobility costs are assumed to equal zero. However, the predictions of the model are not affected when positive search costs are introduced in the model.

${ }^{5}$ Note that job duration is often considered to be an indicator of quality. However, job duration is theresult of high job quality, but not so much a good indicator. That is, some recently started employment relationships can be very good, even though tenure in the job is still very low. Job satisfaction however is able to measure job quality even for such jobs.

${ }^{6}$ Where a drop (gain) in the wage is defined as a decrease (increase) of more than 5 percent relative to the hourly wage in the previous job. The complete cross-tabulation can be found in Table 7 .

${ }^{7}$ For women, job changes may serve to gradually leave the labor market for child care reasons, while job mobility after that may serve to facilitate re-entering the labor market gradually. Though interesting, these job changes may not serve to find the most productive match in the labor market. Note that some older workers may already be at the end of their job search process. However, sensitivity results indicate that the results remain unchanged when I restrict the sample to individuals who are observed in the data from early ages onwards.

${ }^{8}$ Note that promotions are not being part of this quit definition, which only covers employer changes.

${ }^{9}$ Note that the distinction between quits and layoffs is not always straightforward (see also McLaughlin (1991)), as someone may report having left intentionally after being notified of an upcoming dismissal. Nevertheless, the distinction between quits and layoffs seems economically meaningful since the share of workers reporting a drop in job satisfaction after a job change (without an intervening unemployment spell) is much higher for workers who changed jobs due to layoff (30 percent) than for workers who left for a better job (19 percent).

${ }^{10} \mathrm{~A}$ similar picture can be made for those who change jobs following a layoff and for those who get promoted (not presented in paper; available from the author upon request). However, contrary to the graph for job quitters, both graphs are rather flat, the only difference being that average job satisfaction among those being promoted is similar to that of stayers while the average job satisfaction among those being laid off is slightly lower.

${ }^{11}$ The difference in job satisfaction in the year after the job quit are significantly different.

${ }^{12}$ Note from Figure 1 that after two years job satisfaction of multiple-time quitters seems to catch up again. This might be the result of a subsequent job quit: about 64 percent of all multiple-time quitters changes jobs again within two years. 
${ }^{13}$ The advantage of this approach is that all observations for individuals whose satisfaction score changes at least once are included, while a common threshold implies that only those individuals are included whose satisfaction score crosses the given threshold.

${ }^{14}$ Note that the results are unchanged when $y_{i t}$ is defined as $y_{i t}=1$ if $J S_{i t}>c_{i}$ and 0 otherwise.

${ }^{15}$ Including a dummy variable for other types of separations does not improve the model fit. Furthermore, job satisfaction appears to decrease after a layoff, while a small positive effect is found for promotions.

${ }^{16}$ From other studies we know that low job satisfaction predicts future quits. However, the positive effect of job quits on later job satisfaction is not just pure mean reversion (which would arise if only the learning model would be in place), because the positive effects are not just found for unhappy job quitters but also for job quitters who were quite happy with their old job already. Furthermore, if the pattern would be pure mean reversion, then the variance in job satisfaction following a job quit should be similar to the variance in job satisfaction following other types of separation (i.e. layoff or promotion). Figure 5 shows that this is not the case, and that quitters are selective in the new job they accept resulting in a lower variance.

${ }^{17}$ The number of job quits before the start of the sample is censored. However, this is assumed to be captured by the individual fixed effect.

${ }^{18}$ Note that this is conditional on the worker having decided to leave his job. The probability of leaving a job if lower for people in good jobs, regardless of ex ante information availability.

${ }^{19}$ The implicit assumption here is that accepting any job offer that comes along is preferred over having no job at all. This assumption is based on empirical evidence showing that (i) the quality of job offers received is better for employed than for non-employed (e.g. Boheim and Taylor (2002)) and that (ii) employed job search is more effective than unemployed search (e.g. Blau and Robins (1990), Longhi and Taylor (2011)). Labor market entrants are defined as those whose main labor market position is fulltime education in one year and being employed in the next. Note that job satisfaction in the first year of the new accepted job is used. Sensitivity checks, where different distributions are chosen, will be presented later in this section.

${ }^{20}$ Here, I assume that the underlying "true" distribution is normally distributed. When I would assume a uniform distribution with multiple job offers, the optimization procedure could not converge to a likely distribution.

${ }^{21}$ Hence, 1 minus this share represents the importance of learning about job quality.

${ }^{22}$ A similar variance decomposition for promotions yields approximately similar results (0.669). For layoffs, however, starting in a new job is much more risky (0.443).

${ }^{23}$ The results for those with job satisfaction in the old job less than or equal to 2 should be interpreted with caution. This number is slightly higher than 1 , because the actual variation is nearly equal to the variation as predicted by the stepping-stone model. However, there were very few men who were hired from unemployment who reported job satisfaction of level 1 or $2(\mathrm{~N}=42$ and $\mathrm{N}=62$, respectively). Hence, the predicted variance, and hence the result, is probably not be very precise.

${ }^{24}$ Note that in this situation job changes by workers who reported being completely satisfied in the old job $\left(J S^{k}=7\right)$ can still occur if $J S^{*, k}<J S^{*, k+1}$ although only $J S^{k}=J S^{k+1}=7$ is observed in the data.

${ }^{25}$ The final year is either the year before a new job quit occurs, or the last year in which the worker is observed in the sample. 
${ }^{26}$ The extremely high variance for the most dissatisfied job stayers may be due to a relatively low number of observations. Alternatively, it may be the case that this extreme dissatisfaction may make people try very hard to achieve a certain change in their job, where this turns out to be either very successful (i.e. high satisfaction in the next year) or very unsuccessful (i.e. very low satisfaction in the next year). Alternatively, satisfied workers may also receive such offers, but the low variance results from their satisfaction level being close to the upper limit of the satisfaction scale already.

Table 7 Cross-tabulation wage and job satisfaction changes

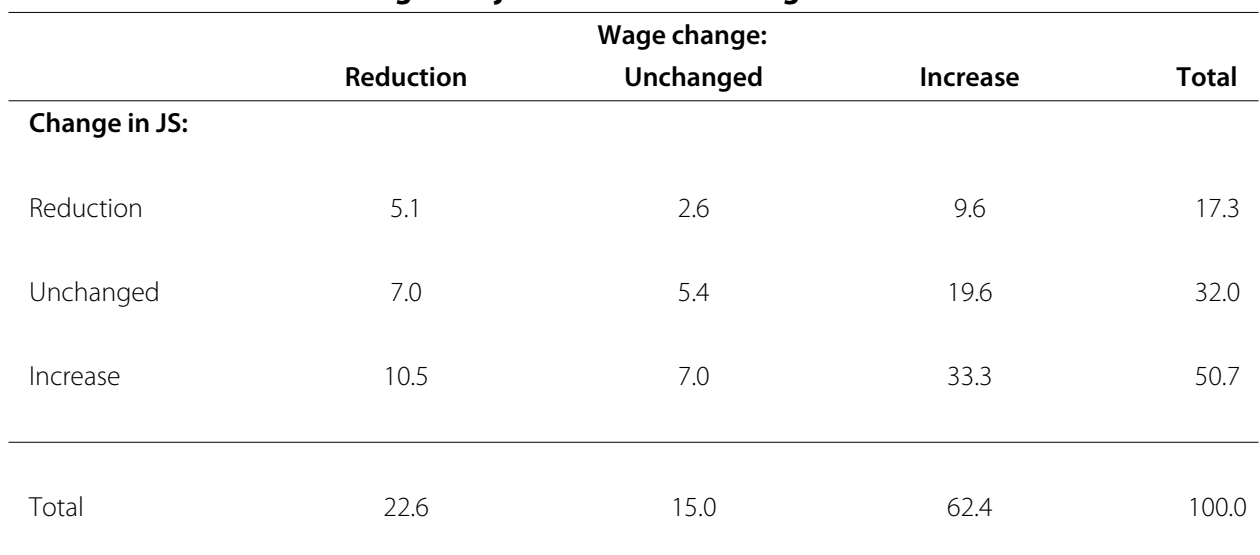

Note: Table presents cell percentages. Wage changes are defined as having a change in the real hourly wage of more than 5 percent.

Source: BHPS.

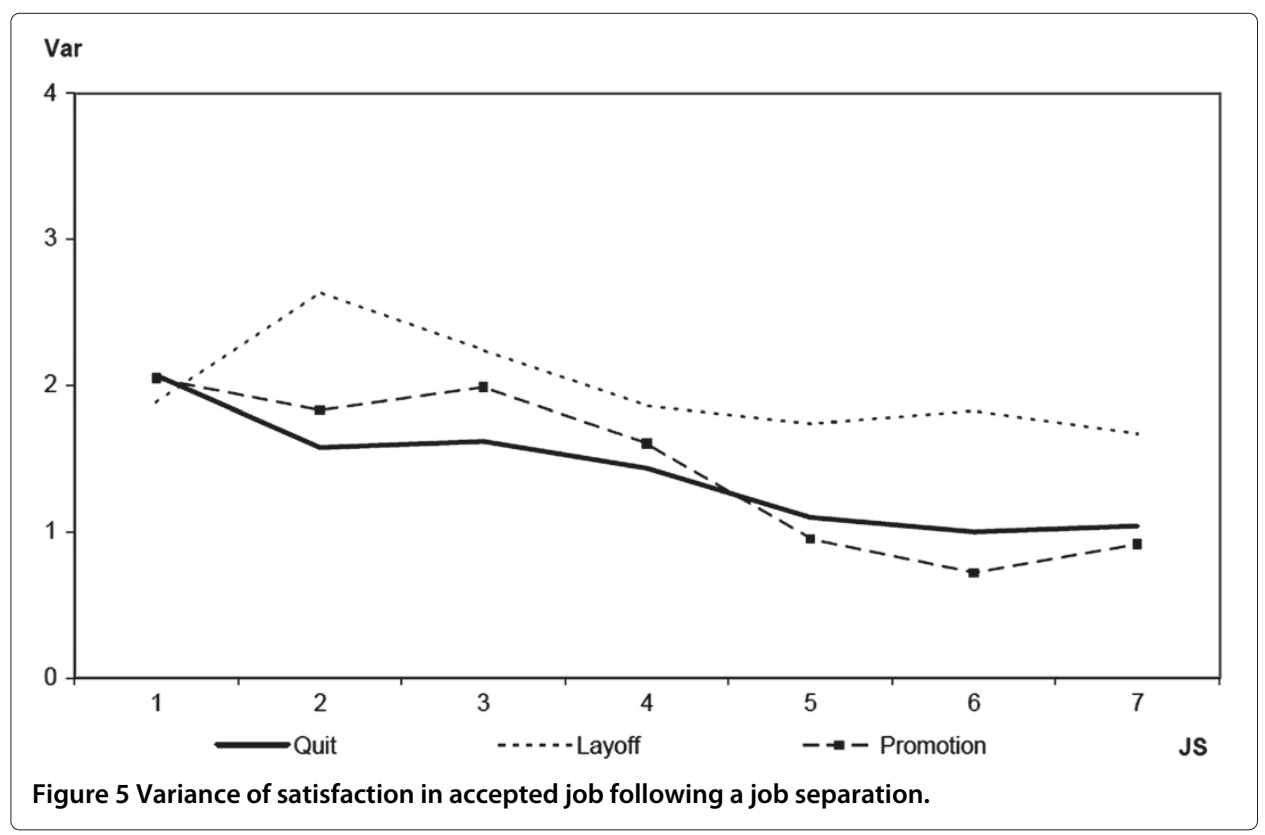




\section{Competing interests}

The IZA Journal of European Labor Studies is committed to the IZA Guiding Principles of Research Integrity. The author declares that she has observed these principles.

\section{Acknowledgements}

The author would like to thank Lex Borghans, Arnaud Dupuy, Bart Golsteyn, Dan Hamermesh, Erzo Luttmer, Rob McMillan, Bob Pollak, Trudie Schils, Jeffrey Smith, an anonymous referee, seminar participants at Maastricht University, IZA and AIAS, and conference participants at the 2008 EALE and SOLE, and the 2009 IZA/SOLE conferences for helpful suggestions.

Responsible editor: Alan Barrett

Received: 14 June 2013 Accepted: 23 July 2013

Published: 7 August 2013

\section{References}

Akerlof G, Rose A, Yellen J, Hall L, Hall R (1988) Job switching and job satisfaction in the u.s. labor market. Brookings Paper on Econ Act 2: 495-594

Altonji J, Paxson C (1986) Job characteristics and hours of work. Res in Labor Econ 8(A): 1-55

Berry K, Mielke P (1992) Assessment of variation in ordinal data. Percept Mot Skills 74: 63-66

Blair J, Lacy MG (2000) Statistics of ordinal variation. Sociol Methods \& Res 28(3): 251-280

Blanchflower D (2008) Happiness economics. NBER Reporter 2

Blau F, Robins P (1990) Job search outcomes for the employed and unemployed. J Pol Econ 98(3): 637-655

Bockermann P, Ilmakunnas P (2009) Job disamenities, job satisfaction, quit intentions, and actual separations: Putting the pieces together. Ind Relat 48(1): 73-96

Boheim R, Taylor M (2002) The search for success: Do the unemployed find stable employment? Labour Econ 9(6): 717-735

Booth A, Francesconi M, Frank J (2002) Temporary jobs: Stepping stones or dead ends? The Econ J 112118(480): F189-F213 Burdett K (1978) A theory of employee job search and quit rates. The Am Econ Rev 68(1): 212-220

Chamberlain G (1980) Analysis of covariance with qualitative data. Rev Econ Stud 47: 225-238

Chi W, Freeman R, Kleiner M (2008) Does changing employers improve job satisfaction? Mimeo.

Christensen B, Lenz R, Mortensen D, Neumann G, Werwatz A (2005) On-the-job search and the wage distribution. J Labor Econ 23(1): 31-58

Clark A, Georgellis Y, Sanfey P (1998) Job satisfaction, wage changes and quits: Evidence from germany. Res Labor Econ 17: $95-121$

Cornelißen T (2009) The interaction of job satisfaction, job search, and job changes. an empirical investigation with german panel data. J Happiness Stud 10: 367-384

Farber HS (1999) Mobility and stability: The dynamics of job change in labor markets. In: Ashenfelter O, Card D (eds) Handbook of labor economics, Volume 3B. Elsevier, Amsterdam, pp 2439-2483

Ferrer-i Carbonell A, Frijters P (2004) How important is methodology for the estimates of the determinants of happiness? The Econ J 114(July): 641-659

Freeman R (1978) Job satisfaction as an economic variable. Am Econ Rev 68(2): 135-141

Green F. (2010) Well-being, job satisfaction and labour mobility. Labour Econ 17: 897-903

Jovanovic B (1979) Job matching and the theory of turnover. J Pol Econ 87: 972-990

Jovanovic, B (1984) Matching, turnover, and unemployment. J Pol Econ 91 (1): 108-122

Kambourov G, Manovskii I (2008) Rising occupational and industry mobility in the united states: 1968-97. Int Econ Rev 49(1): 41-79

Levy-Garboua L, Montmarquette C, Simonnet V (2007) Job satisfaction and quits. Labour Econ 14: 251-268

Light A (2005) Job mobility and wage growth: Evidence from the nlsy79. Monthly Labor Rev 128(2): 33-39

Light A, McGarry K (1998) Job change patterns and the wages of young men. Rev Econ Stat 80(2): 276-286

Longhi S, Taylor M (2011) Explaining differences in job search outcomes between employed and unemployed job seekers. IZA Discussion Paper 5860, Bonn.

MacDonald G (1988) Job mobility in market equilibrium. The Rev Econ Stud 55(1): 153-168

McCall B (1990) Occupational matching: A test of sorts. The J Pol Econ 98(1): 45-69

McLaughlin A (1991) A theory of quits and layoffs with efficient turnover. The J Pol Econ 99(1): 1-29

Munasinghe L, Sigman K (2004) A hobo syndrome? mobility, wages, and job turnover. Labour Econ 11: 191-218

Neal D (1999) The complexity of job mobility among young men. J Labor Econ 17(2): 237-261

Neumark D (2002) Youth labor markets in the united states: Shopping around vs. staying put. The Rev Econ Stat 84(3): 462-482

Oswald AJ, Wu S (2009) Objective confirmation of subjective measures of human well-being: Evidence from the usa. Science 327(5965): 576-579

Perez Jl, Rebollo YS (2005) Wage changes through job mobility in europe: A multinomial endogenous switching approach. Labour Econ (4): 531-555

Postel-Vinay F, Robin JM (2002) The distribution of earnings in an equilibrium search model with state-dependent offers and counter-offers. Int Econ Rev 43(4): 989-1016

Sousa-Poza A, Henneberger F (2004) Analyzing job mobility with job turnover intentions: An international comparative study. J Econ Issues 38(1): 113-137

Stutzer A, Frey BS (2008) Stress that doesn't pay: The commuting paradox. The Scandinavian J Econ 110(2): 339-366

doi:10.1186/2193-9012-2-7

Cite this article as: Gielen: Repeated job quits: stepping stones or learning about quality?. IZA Journal of European Labor Studies 2013 2:7. 